\title{
Classifying low formaldehyde emission from blockboard by gas analysis method and desiccator method
}

\author{
Yu Haixia ${ }^{\mathrm{a}}$, Ma Xuan ${ }^{\mathrm{b}}$, Yang Liu ${ }^{\mathrm{c}}$, Fang Chongrong ${ }^{\mathrm{d}}, \mathrm{Xu} \mathrm{Manping}^{\mathrm{e}}$ \\ aivyyhx@126.com, b31778657@qq.com, ㄷ8802286@qq.com, ${ }^{\mathrm{d}}$ chinafcr@hotmail.com, \\ exump66@hotmail.com
}

\author{
Zhejiang Forestry Product Testing Station ( Zhejiang Provincial Key Laboratory of Biological and \\ Chemical Utilization of Forest Resources ), Hangzhou, 310023, Zhejiang, China
}

\begin{abstract}
Keywords: Blockboard; formaldehyde emission; desiccator method; gas analysis method; moisture content

Abstract. The paper studied formaldehyde emission (FE) of $\mathrm{E}_{0}$ class blockboards by desiccator and gas analysis method. Results showed that for the same formaldehyde emission value got from desiccator method, the gas analysis (GA) values were quite different. It was suggested to use gas analysis method to evaluate formaldehyde emission at low formaldehyde content. The main reason for different gas analysis values was moisture content (MC), the lower the board moisture content the smaller the formaldehyde emission value. Gas analysis value was very sensitive to specimen's moisture content, it was suggested to keep low moisture content could be a solution to decrease formaldehyde emission for blockboards.
\end{abstract}

\section{Introduction}

Blockboards, a kind of plywood with the solid-wood strip core inside, are widely used in interior decoration application in China [1]. However formaldehyde-based resin adhesives especially urea-formaldehyde (UF) resin were widely used as bonding material which caused formaldehyde emission during long term utilization [2]. The International Agency for Research on Cancer (IARC) reclassified formaldehyde as"carcinogenic to human (Group 1)" from "probable carcinogenic to human (Group 2A)"in 2004 [3]. Test methods were invented to quantify FE such as desiccator method, chamber method, perforator method, gas analysis etc [4-7]. Desiccator method, originally came from Japan[8] was commonly used to test FE from blockboard and plywood $[9,10]$. Desiccator test should pre-treatment the sample for 7 days plus 24 hours sampling period [10]. Gas analysis method, originated from Europe [11] shorts test period from 8 days to 4 hours by high temperature $\left(60^{\circ} \mathrm{C}\right)$ and air flow rate, the method were adopted by China [12] and ISO [13]. Emission classes of $\mathrm{E}_{0}(\leq 0.5 \mathrm{mg} / \mathrm{L}), \mathrm{E}_{1}(\leq 1.5 \mathrm{mg} / \mathrm{L})$, and $\mathrm{E}_{2}(\leq 5 \mathrm{mg} / \mathrm{L})$ were established by China national standard for blockboard [9]. The values measured by EN 717-2 were under the $\mathrm{E}_{1}$ emission class $\left(E_{1} \leq 3.5 \mathrm{mg} / \mathrm{m}^{2} \mathrm{~h}\right)$ and $E_{2}$ emission class $\left(E_{2} \leq 8 \mathrm{mg} / \mathrm{m}^{2} \mathrm{~h}\right)$ for plywood according to BS EN 13986 since 2004 [14].

The paper studied $\mathrm{FE}$ of $\mathrm{E}_{0}$ class blockboards by desiccator and gas analysis method, compared FE values of the two methods and analyzed the influence factors. The objectives of this study were to investigate the possibility of using gas analysis method to evaluate formaldehyde released from blockboards, differentiate low formaldehyde emission and short test period.

\section{Materials and methods}

Blockboard specimens Ten pieces of $\mathrm{E}_{0}$ class blockboards from different brand manufactures by size of $2440 \times 1220 \times 12 \mathrm{~mm}$ (length by width by thickness) were brought from building material market. Then cut into $150 \times 50 \mathrm{~mm}$ (10 pieces) and 400×50 mm ( 3 pieces) (length by width) for desiccator and gas analysis test, respectively. The four edges of $400 \times 50 \mathrm{~mm}$ specimens were sealed with aluminium-foil paper. 
FE test method For desiccator method, test pieces were placed in a $20{ }^{\circ} \mathrm{C}$ desiccator $(10 \mathrm{~L})$ containing a vessel with $300 \mathrm{~mL}$ distilled water (Fig. 1) for $24 \mathrm{~h}$. The formaldehyde release was expressed by the formaldehyde concentration of $300 \mathrm{~mL}$ distilled water $(\mathrm{mg} / \mathrm{L})$ [10]. Gas analysis test was carried out in a closed chamber with $60^{\circ} \mathrm{C}$ temperature and less than $3 \% \mathrm{RH}$ for $4 \mathrm{~h}$. Formaldehyde released from the test piece mixes with the air in the chamber. This air was continually drawn from the chamber with $1 \mathrm{~L} / \mathrm{min}$ rate and passed through 4 groups of gas wash bottles, containing approximately $20 \mathrm{~mL}$ water, which absorb the released formaldehyde (Fig. 2). The formaldehyde release was calculated from this concentration, the sampling time and the exposed area of the test piece and was expressed in milligrams per square meter and per hour $\left(\mathrm{mg} / \mathrm{m}^{2} \mathrm{~h}\right)[11-13]$.
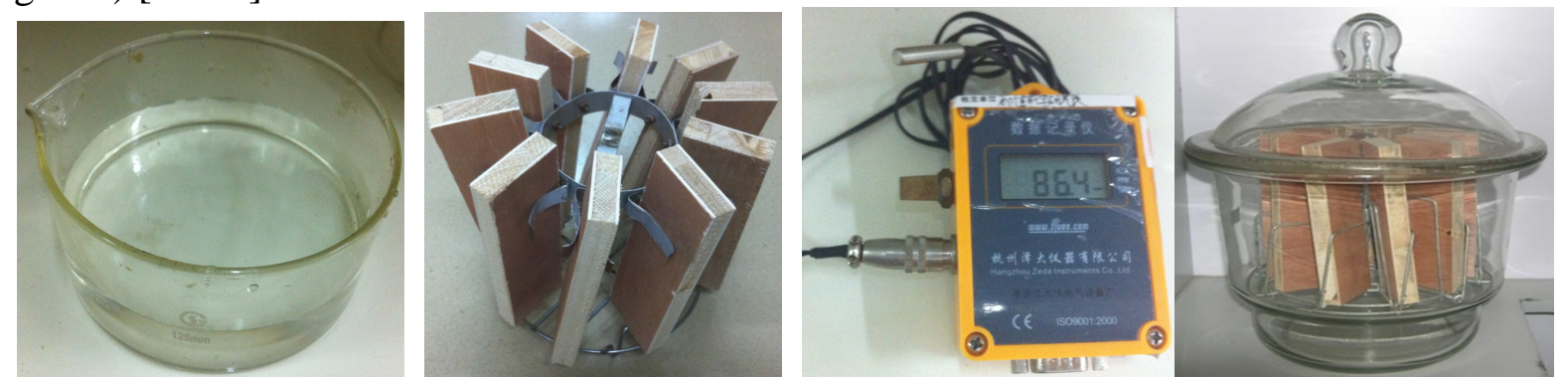

Fig.1 Desiccator test for formaldehyde emission (from left to right were beaker with $300 \mathrm{~mL}$

distilled water; blockboard specimens; temperature and humidity recorder; 10L desiccator with samples, respectively)

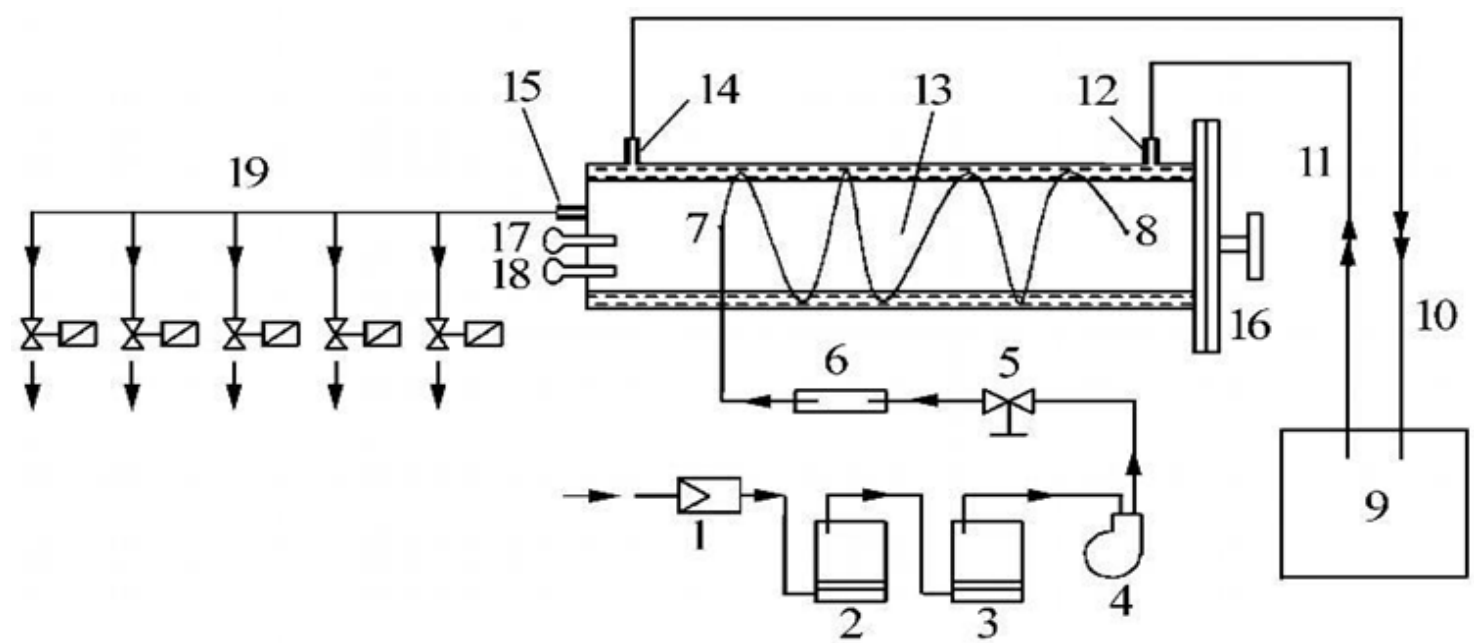

1. Air filter, 2. Wash bottle, 3. Desiccator, 4. Air pump, 5. Needle valve, 6. Equipment for measurement of air flow, 7. Inlet of air (test chamber), 8. Outlet of test air, 9. Heat medium, 10. Come back water tube, 11. Inlet of water tube, 12. Water inlet, 13. Test chamber, 14. Water outlet, 15. Outlet of mixed air, 16. Door, 17. Temperature monitor, 18. Pressure monitor, 19. Magnetic valves.

Fig.2 Formaldehyde emission test apparatus using the gas analysis method

\section{Results and discussion}

Formaldehyde emission values tested by gas analysis and desiccator method The GA values for $0.3,0.4$ and $0.5 \mathrm{mg} / \mathrm{L}$ from desiccator method ranged from $0.6-1.2,1.5-2.2$, and $1.5-3.2 \mathrm{mg} / \mathrm{m}^{2} \mathrm{~h}$, respectively. However, most of the values were lower than the corresponding level of gas analysis method got from linear regression from $\mathrm{E}_{\mathrm{I}}$ and $\mathrm{E}_{2}$ class described by two methods $(\mathrm{y}=1.2857 \mathrm{x}+1.5714)$. Test result (table 1$)$ showed that gas analysis values were below the standard limit lower than expected. Table 1 also showed that for same FE value got from desiccator method, 
the gas analysis value were varied, so it can classify the FE further on at very low formaldehyde emission level.

Table 1 FE value test by GA method and desiccator method and corresponding FE limitations

\begin{tabular}{|l|l|l|l|l|l|l|}
\hline Test method & Unit & \multicolumn{5}{|c|}{ Emission level } \\
\hline Desiccator method & {$[\mathrm{mg} / \mathrm{L}]$} & 0.3 & 0.4 & $0.5\left(\mathrm{E}_{0}\right)$ & $1.5\left(\mathrm{E}_{1}\right)$ & $5\left(\mathrm{E}_{2}\right)$ \\
\hline GA method & {$\left[\mathrm{mg} / \mathrm{m}^{2} \mathrm{~h}\right]$} & 2 & 2.1 & 2.2 & 3.5 & 8 \\
\hline AG average(range) & {$\left[\mathrm{mg} / \mathrm{m}^{2} \mathrm{~h}\right]$} & $0.9(0.6-1.2)$ & $1.6(1.5-2.2)$ & $2.1(1.5-3.2)$ & - & - \\
\hline
\end{tabular}

Effect of relative humidity on FE values by GA and desiccator method It was very important to determine the effect of humidity on formaldehyde emission rates. As a result, it has been reported that any change in water content of the product (bonded with UF) may alter formaldehyde release over the short term [15-17]. For desiccator method, with 300mL distill water inside, the 9-11L small closed container will reached almost $100 \%$ relative humidity in short time for empty desiccator, and reached to about $90 \%$ RH within $2 \mathrm{~h}$ with specimen inside(Fig. 3 ).

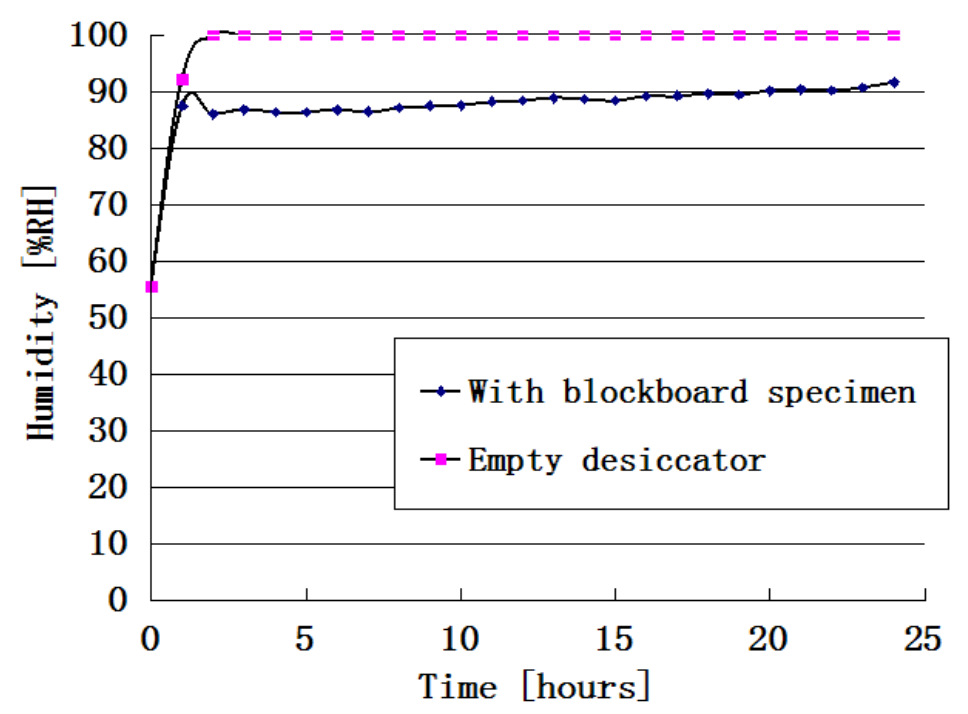

Fig. 3 Relative humidity changes in desiccator during $24 \mathrm{~h}$ test

During test period, $\mathrm{MC}$ in blockboard changed and tried to reach a steady state, when its equilibrium MC below or above atmosphere relative humidity, it will absorb or desorb moisture from air, in the meanwhile, specimen will release or absorb formaldehyde and also reach a steady state in the long term [18] and the initial MC of the sample will play an important role on both of these balance. As reported [19], UF will hydrolyzed when water exist and will speed up with temperature rising.

Effect of moisture content on FE values by gas analysis method Due to high temperature and low humidity, free water in the specimen was easy to evaporate. 
Table 2 Moisture content changes during GA and desiccator test

\begin{tabular}{|c|c|c|c|}
\hline No. & $\begin{array}{c}\text { Specimen } \\
\text { MC[\%] }\end{array}$ & $\begin{array}{c}\text { MC decrease rate for GA } \\
\text { method[\%] }\end{array}$ & $\begin{array}{c}\text { MC increase rate for } \\
\text { desiccator method[\%] }\end{array}$ \\
\hline 1 & 14.9 & 4.1 & 0.5 \\
\hline 2 & 14.9 & 3.9 & 0.5 \\
\hline 3 & 13.8 & 3.7 & 0.7 \\
\hline 4 & 12.6 & 3.1 & 0.6 \\
\hline 5 & 12.5 & 3.1 & 0.6 \\
\hline 6 & 11.7 & 2.1 & 0.5 \\
\hline 7 & 11.7 & 2.0 & 0.5 \\
\hline 8 & 10.7 & 2.0 & 0.6 \\
\hline 9 & 10.6 & 1.8 & 0.4 \\
\hline 10 & 10.4 & 1.9 & 0.6 \\
\hline
\end{tabular}

Table 2 showed the higher the MC the greater the decrease values. The decease rate ranged from 1.8 to $4.1 \%$ after $4 \mathrm{~h} 60^{\circ} \mathrm{C}$ test, the evaporation will carry out a few amount formaldehyde consequently accelerate the FE rate. Moisture content closely related with formaldehyde release for GA test. In contrast, moisture content increased a little $(0.4$ to $0.7 \%)$ for desiccator test which may explain the less influence by MC.
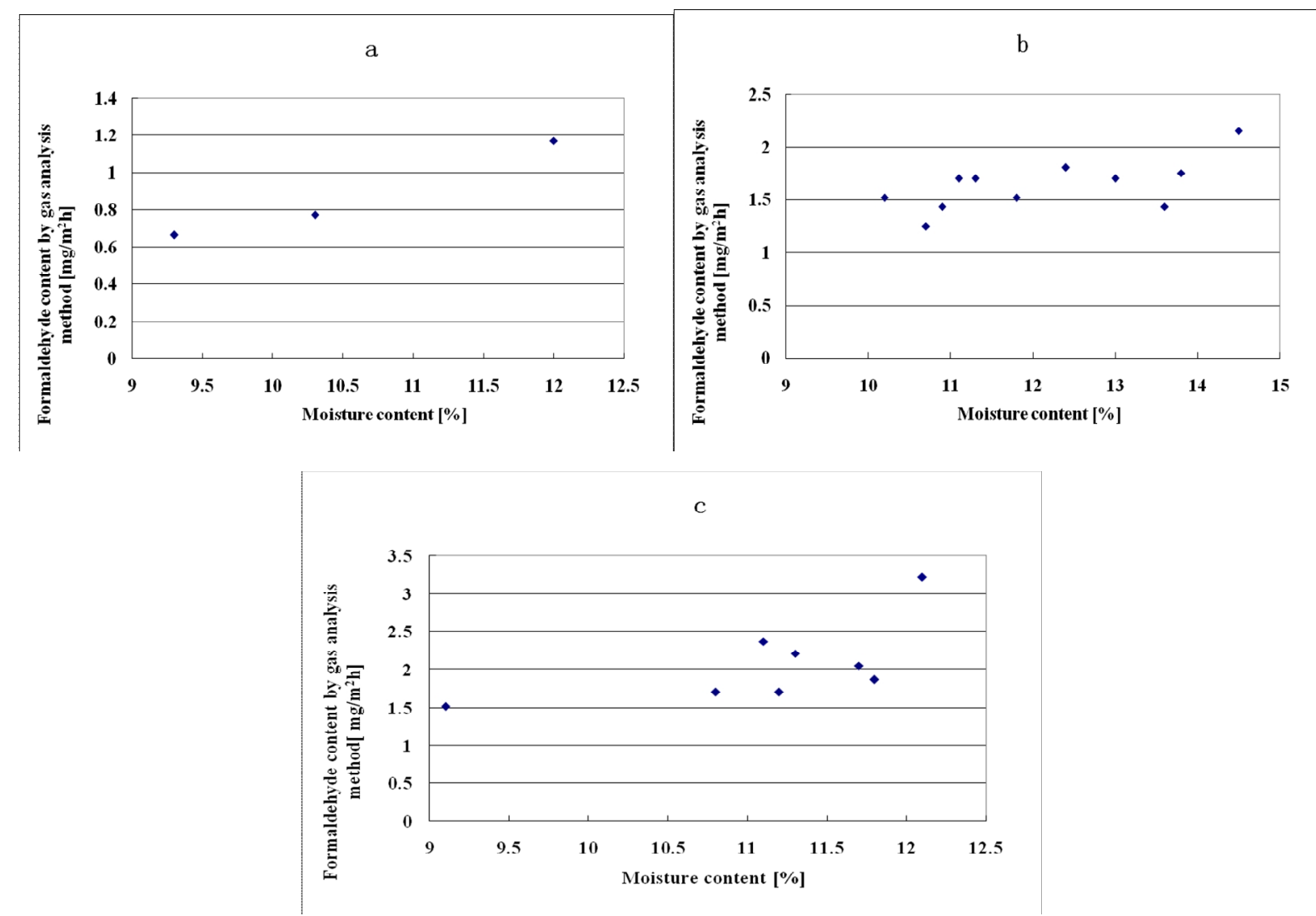

Fig. 4 Influence of MC on FE tested by GA method (Desiccator method value: a. $0.3 \mathrm{mg} / \mathrm{L}$, b. $0.4 \mathrm{mg} / \mathrm{L}$, and c. $0.5 \mathrm{mg} / \mathrm{L})$ 
Fig. 4 showed that FE were closely related to MC, the lower the board moisture content the smaller the formaldehyde emission value. This was in agree with previous study by Long[20]. Gas analysis value were very sensitive to specimen's moisture content, to keep low moisture content could be a solution to decrease formaldehyde emission for blockboards.

\section{Conclusions}

Formaldehyde emission values of $\mathrm{E}_{0}$ class blockboard got from desiccator method were quite different from GA values, the corresponding averages of FE values of GA method for $0.3,0.4$, and $0.5 \mathrm{mg} / \mathrm{L}$ by desiccator method were $0.9,1.6$ and $2.1 \mathrm{mg} / \mathrm{m}^{2} \mathrm{~h}$, respectively. GA method can further classify FE value low FE products. It was suggested to use GA method to evaluate FE properties at low formaldehyde emission. The main reasons for the differences were originating from $\mathrm{MC}$, the lower the MC the smaller the FE value. GA value were very sensitive to MC, to keep low MC could be a solution to decrease FE value for blockboard.

\section{Acknowledgment}

The authors appreciate financial support from Cooperation projects between Zhejiang province and Chinese Academy of Forestry (NO. 2014SY11).

\section{References}

[1] http://www.fao.org/forestry/statistics/80570/en/

[2] Z. Wang , J. Wei, Releasing Characteristics of Formaldehyde from Block Board, Journal of Environmental Hygiene. 3(5)(2013)449-451.

[3] https://en.wikipedia.org/wiki/International_Agency_for_Research_on_Cancer

[4] R.S. Maria, L. Annelise, V. Ewa, W. Andersl, Formaldehyde emission-Comparison of different standard methods, Atmospheric Environment. 41 (2007) 3193-202.

[5] Z.M. Salem Mohamed, B. Martin, S. Jaromír, B. Jitka, Evaluation of formaldehyde emission from different types of wood-based panels and flooring materials using different standard test methods, Building and Environment. 49 (2012) 86-96.

[6] M. Risholm-Sundman, A. Larsen, E. Vestin, A. Weibull, Formaldehyde emission-a comparison of different standard methods, In: Proc Indoor Air. (2005) 1925-1930.

[7] M. Risholm-Sundman, N. Wallin, Comparison of different laboratory methods for determining the formaldehyde emission from three-layer parquet floors, Holz Roh-Werkst. 57 (1999)319-324.

[8] JIS A 1460, Building boards Determination of formaldehyde emission-Dedicator method, Japanese Industrial Standards.2001(Revised in 2005).

[9] GB/T 9846, Blockboard, Chinese national standard. General Administration of Quality Supervision, Inspection and Quarantine of the People's Republic of China. (2006).

[10] GB/T 17657, Test methods of evaluating the properties of wood-based panels and surface decorated wood-based panels, Chinese national standard. General Administration of Quality Supervision, Inspection and Quarantine of the People's Republic of China. 1999 (Revised in 2013).

[11] EN 717-2, Wood-based panels. Determination of formaldehyde release. Part 2: formaldehyde release by the gas analysis method, European Norm. (1995). 
[12] GB/T 23825, Wood-based panels-Determination of formaldehyde release-gas analysis method, Chinese national standard. General Administration of Quality Supervision, Inspection and Quarantine of the People's Republic of China. (2009).

[13] ISO 12460-3, Wood-based panels-Determination of formaldehyde release Part 3: Gas analysis method, International Standardization Organization. (2008).

[14] BS EN 13986, Wood-based panels for use in construction - Characteristics, evaluation of conformity and marking, , European Norm. (2004).

[15] K.F. LI , X.J. HOU, S.H. XU, W.X. PENG, Effect of Test Methods on Plywood Formaldehyde Emission Content, CHINA WOOD INDUSTRY. 19(1) (2005)30-32.

[16] J.F. Lin, Study on the Emission Law of Formaldehyde from man-made board of Indoor Decoration, Chemical Engineering \& Equipment. 3(2013)41-43.

[17] G.J. Sun, H. Wang, The methods to reduce the content of free formaldehyde in particle board, wood processing machinery. 1(2002)21-23.

[18] W.X. Wang, The relative humidity in the air and man-made board of determination method of formaldehyde to release a few questions, China Wood-Based Panels. 12 (33)(2012)31-33.

[19] G.E. Myers, Effect of temperature and humidity on formaldehyde emission from UF-bonded boards: a literature critique, For Prod J. 35(9) (1985)20-31.

[20] L. LONG, X.X. LU, Effects of moisture content of wood-based panels on formaldehyde releases, Journal of Beijing Forestry University. 27(5) (2005) 98-102. 